\title{
Perancangan Aplikasi E-Ticketing Pada Agen Bus Berbasis Website Menggunakan Laravel
}

\author{
Muhammad Haidar Wijaya ${ }^{1}$, Magdalena A. Ineke Pakereng ${ }^{2}$ \\ ${ }^{1,2}$ Universitas Kristen Satya Wacana; Jl. Diponegoro 52-60 Salatiga - Indonesia 50711, \\ (0298)321212 \\ ${ }^{3}$ Jurusan Teknik Informatika, Fakultas Teknologi Informasi UKSW, Salatiga \\ e-mail: ${ }^{1} 672017154 @$ student.uksw.edu, ${ }^{2}$ ineke.pakereng@uksw.edu
}

\begin{abstract}
Abstrak
Bus merupakan transportasi yang masih menjadi pilihan utama masyarakat yang mudah dijangkau, dengan membeli tiket melalui agen bus masyarakat bisa menikmati layanan bus. Namun dalam proses transaksinya pelanggan harus mengunjungi agen bus untuk melakukan transaksi pembelian tiket. Hal ini tentunya sangat tidak praktis dan tiket yang telah dibeli juga rentan akan kerusakan dan rawan hilang. Oleh karena itu diperlukan sebuah sistem e-ticketing untuk mendukung proses transaksi yang lebih efisien dan meminimalisir kerusakan dan kehilangan pada tiket. Framework laravel digunakan dalam pembuatan website karena dalam framework laravel menyediakan sistem mail gateway yang mempermudah dalam pelayanan tiket kepada pelanggan. Hasil dari perancangan aplikasi ini adalah sebuah website e-ticketing yang dapat membantu masyarakat dalam membeli tiket bus dan meminimalisir kerusakan dan kehilangan pada tiket.
\end{abstract}

Kata kunci e-ticketing, mail gateway, framework laravel, agen bus.

\begin{abstract}
Bus is the transportation which is still the main choice for the community which is easily reached, by buying a ticket through a bus agent the community can enjoy the bus. However, in the transaction process the customer must visit a bus agent to make a ticket purchase transaction. This is of course very impractical and the tickets that have been purchased are also vulnerable to damage and prone to loss. Therefore, an e-ticketing system is needed to support a more efficient transaction process and minimize damage and loss of tickets. The laravel framework is used in making websites because the laravel framework provides a mail gateway system that makes ticketing services easier to customers. The result of designing this application is an e-ticketing website that can help the public in buying bus tickets and minimize damage and loss to tickets.
\end{abstract}

Keywords e-ticketing, mail gateway, laravel framework, bus agency.

\section{PENDAHULUAN}

Sekian banyaknya moda transportasi yang tersedia saat ini membuat masyarakat banyak menggunakannya sebagai sarana penunjang aktivitas, mulai dari sarana perjalanan antar daerah, sebagai sarana untuk melakukan bisnis, hingga berangkat ke sekolah atau tempat bekerja, masyarakat sangat mengandalkan transportasi. Beberapa transportasi yang tersedia, seperti bus masih menjadi pilihan utama masyarakat untuk melakukan perjalanan antar daerah, berangkat sekolah atau kantor, bukan hanya harganya yang murah, juga fasilitas yang ditawarkan tidak kalah jauh dari transportasi lainnya. Bus juga menjadi transportasi yang sangat mudah dijangkau oleh masyarakat. Untuk menggunakan layanan bus ini masyarakat bisa datang ke agen bus terdekat untuk membeli tiket perjalanan. 
Dalam proses pembelian tiketnya, pelanggan harus terlebih dahulu mengunjungi agen bus terdekat untuk membeli sebuah tiket, jika tiket sudah dibeli maka pelanggan dapat menggunakan layanan bus sepenuhnya. Hal ini tentunya sangat tidak praktis dan rentan akan terjadinya kerusakan pada tiket yang sudah dibeli, serta rentan dengan kehilangan tiket. Ketidak praktisan terjadi pada saat proses transaksi yang mengharuskan pelanggan mengunjungi agen bus terlebih dahulu untuk membeli tiket, hal ini dapat membuang waktu pelanggan yang berharga. Kemudian kerusakan tiket bisa saja terjadi, hal ini dikarenakan agen bus masih menggunakan tiket fisik, dengan menggunakan tiket fisik bisa saja tiket hilang atau rusak karena terlalu banyak tekukan pada tiket. Padahal dengan kemajuan teknologi yang pesat saat ini seharusnya agen bus sudah beralih menggunakan metode $e$ ticketing, suatu cara untuk mendokumentasikan proses penjualan dari aktifitas perjalanan pelanggan, tanpa harus mengeluarkan dokumen secara fisik maupun paper ticket [1]. Berdasarkan masalah yang telah dijelaskan tadi, maka latar belakang penelitian ini adalah membuat sistem untuk layanan pembelian tiket atau e-ticketing yang bisa digunakan pelanggan untuk mengurangi waktu yang digunakan pelanggan untuk membeli tiket dari agen bus serta melakukan pembelian tiket secara langsung dari mana saja, dan kapan saja. Dan sebagai sarana untuk dan mencegah kerusakan dan kehilangan tiket.

Berdasarkan latar belakang yang ada, agen bus membutuhkan sebuah sistem informasi yang dapat melakukan transaksi pembelian tiket dan pengiriman tiket yang sudah dibeli kepada pelanggan. Sistem informasi operasional ini akan dibangun dengan basis website dengan menggunakan framework laravel. Dengan adanya sistem ini diharapkan akan memudahkan agen bus untuk memberikan pelayanan yang terbaik saat proses transaksi pembelian tiket kepada pelanggan, serta dapat meminimalisir kerusakan pada tiket yang telah dibeli dan mencegah terjadinya kehilangan tiket oleh pelanggan. Penggunaan framework laravel untuk pengembangan sistem ini dikarenakan di dalam framework laravel sendiri sudah memiliki fitur mail gateway. Pada sistem e-ticketing yang dibangun ini juga menampilkan mengenai rute yang tersedia, ketersediaan kursi, dan pemilihan tempat duduk oleh pelanggan hingga total biaya yang harus dibayarkan.

Pada penelitian yang berjudul Perancangan Aplikasi E-Ticketing pada PO.CV Jambi Transport Berbasis Web, membahas tentang pembuatan aplikasi pembantu pelanggan dalam pemesanan tiket, dan pembayaran. Serta membantu perusahaan dalam pemasaran tiket dan pencatatan laporan, dalam pembuatan aplikasi masih memiliki kekurangan yang terletak pada keamanan website dan masih belum menggunakan sms gateway untuk mengirimkan tiket yang sudah dipesan [2]. Kemudian pada penelitian Sistem Reservasi E-Ticketing Pesawat Multi-Tier Terintegrasi Multi-mitra Berbasis Saop (Studi Kasus PT. X-Travel) membahas mengenai pembuatan aplikasi reservasi e-ticketing berbasis SAOP (Simple Object Acces Protokol) yang berbasis $X M L$ untuk sistem transaksi, menyediakan data dan pengolahan data untuk segala informasi mengenai jadwal penerbangan, pemesanan tiket pesawat terbang, dan keseluruhan biaya tiket pesawat terbang [3]. Selanjutnya pada penelitian yang berjudul Rancang Bangun Aplikasi E-Ticketing Travel Antar Kota Berbasis Android membahas tentang aplikasi berbasis android dengan framework PHP. Aplikasi ini memuat informasi berupa ketersediaan tiket travel, jadwal keberangkatan, rute perjalanan, biaya yang dibutuhkan hingga pembelian tiket secara online [4]. Kemudian pada penelitian Pengembangan Aplikasi Mobile Menggunakan Javascript React Native Untuk E-Ticketing Pertandigan Sepakbola aplikasi yang dibuat berupa aplikasi mobile dengan memberikan fitur registrasi untuk dapat memesan tiket pertandingan, pertandingan yang akan datang serta riwayat transaksi pemesanan tiket [5]. Pada penelitian Perancangan Sistem Informasi E-Ticketing Pada Bus Trans Metro Pekanbaru Menggunakan QR Code Berbasis Web, membahas mengenai penggunaan $Q R$ Code sebagai pengganti tiket fisik yang mudah rusak. Dengan menggunakan $Q R$ Code ini dapat memberi efisiensi dalam pelayanan tiket [6]. 


\section{METODE PENELITIAN}

Dalam Perancangan Aplikasi E-Ticketing Pada Agen Bus Bebasis Website Menggunakan Laravel, menggunakan model pengembangan sistem waterfall adalah metode pendekatan secara sistematis dan urut [7]. Ada beberapa tahapan dalam pengembangan sistem yang terbagi menjadi empat tahapan yang dilakukan analisa kebutuhan sistem, desain, coding, dan pengujian, tahapan tahapan tersebut dapat dilihat pada Gambar 1.

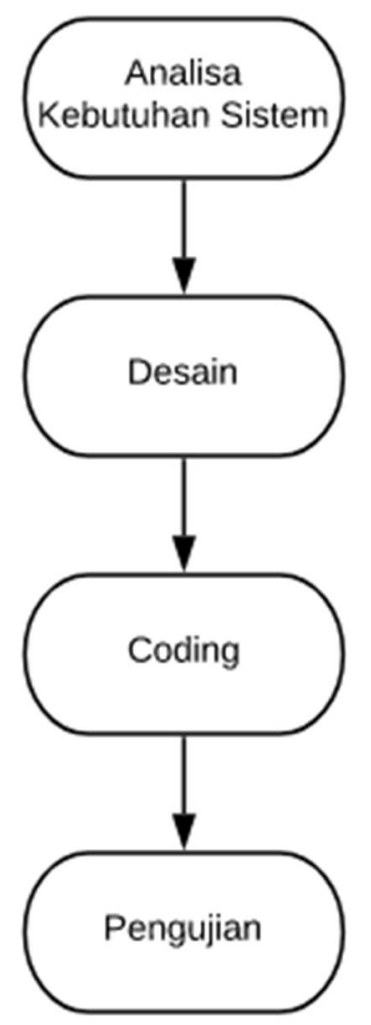

Gambar 1. Tahapan Penelitian

\subsection{Analisa Kebutuhan Sistem}

Tahap ini dilakukan analisa mengenai kebutuhan sistem yang diperlukan dalam perancangan website e-ticketing. Ada beberapa hal yang dilakukan dalam analisa kebutuhan, yaitu:

\subsubsection{Mendefinisikan Masalah}

1) Pada proses transaksi pembelian tiket masih dilakukan dengan pelanggan mengunjungi agen bus.

2) Tiket yang digunakan masihlah tiket fisik yang rentan rusak dan hilang.

\subsubsection{Mendefinisikan Kebutuhan Sistem}

1) Aplikasi dapat melakukan transaksi dimanapun dan kapanpun.

2) Aplikasi dapat mengirim tiket yang telah dibeli oleh pelanggan setelah proses transaksi selesai.

3) Aplikasi memerlukan internet agar dapat diakses.

Muhammad, et., al [Perancangan Aplikasi E-Ticketing pada Agen Bus Berbasis Website Menggunakan Laravel] 


\subsection{Desain}

Pada tahap desain ini, dibuat sebuah Use Case Diagram, Activity Diagram, dan Desain Interface. Berdasarkan analisa kebutuhan sistem pada tahap sebelumnya.

\subsection{Coding}

Pada tahapan ini akan dilakukan coding menggunakan framework laravel berdasakan dari analisa kebutuhan sistem dan desain. Hasil dari tahap ini adalah berupa aplikasi yang sesuai dengan desain yang telah dibuat pada tahap sebelumnya.

\subsection{Pengujian}

Tahap ini dilakukan uji coba sistem yang telah dibuat untuk memastikan semua fungsi aplikasi berjalan sesuai dengan rancangan awal. Serta mengurangi bug yang ada pada aplikasi, untuk pengujian dilakukan dengan menggunakan teknik pengujian blackbox.

\section{HASIL DAN PEMBAHASAN}

Pada bagian ini menjelaskan hasil dari perancangan sistem dan implementasi dari program. Perancangan sistem menggunakan Use Case Diagram dan Activity Diagram. Hasil dari coding akan berupa interface halaman website yang menggunakan framework laravel.

\subsection{Use Case Diagram}

Use Case Diagram adalah deskripsi fungsi dari sebuah system dari sudut pandang para pengguna sistem. Use Case Diagram bekerja dengan menggunakan skenario, yaitu deskripsi urutan langkah yang menerangkan apa yang dilakukan pengguna terhadap sistem maupun sebaliknya [8]. Use Case Diagram yang dibuat ditampilkan pada Gambar 1.

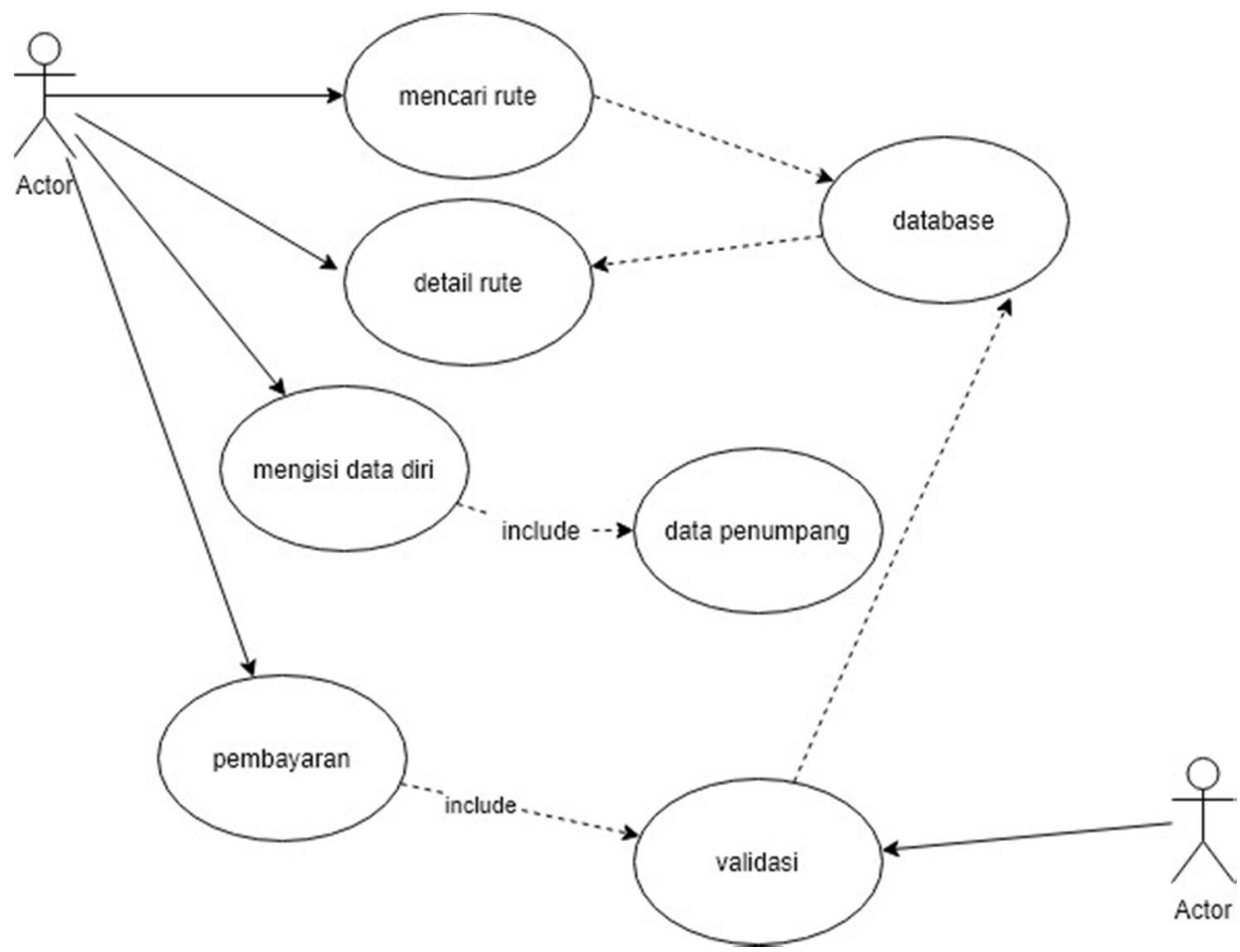

Gambar 2. Use Case Diagram

Muhammad, et., al [Perancangan Aplikasi E-Ticketing pada Agen Bus Berbasis Website Menggunakan Laravel] 


\subsection{Activity Diagram}

Activity Diagram menggambarkan alur aktivitas secara langkah demi langkah dalam sebuah system [9]. Activity Diagram yang dibuat digunakan untuk menunjukan bagaimana proses transaksi e-ticketing yang terjadi pada sistem. Activity Diagram ditampilkan pada Gambar 2.

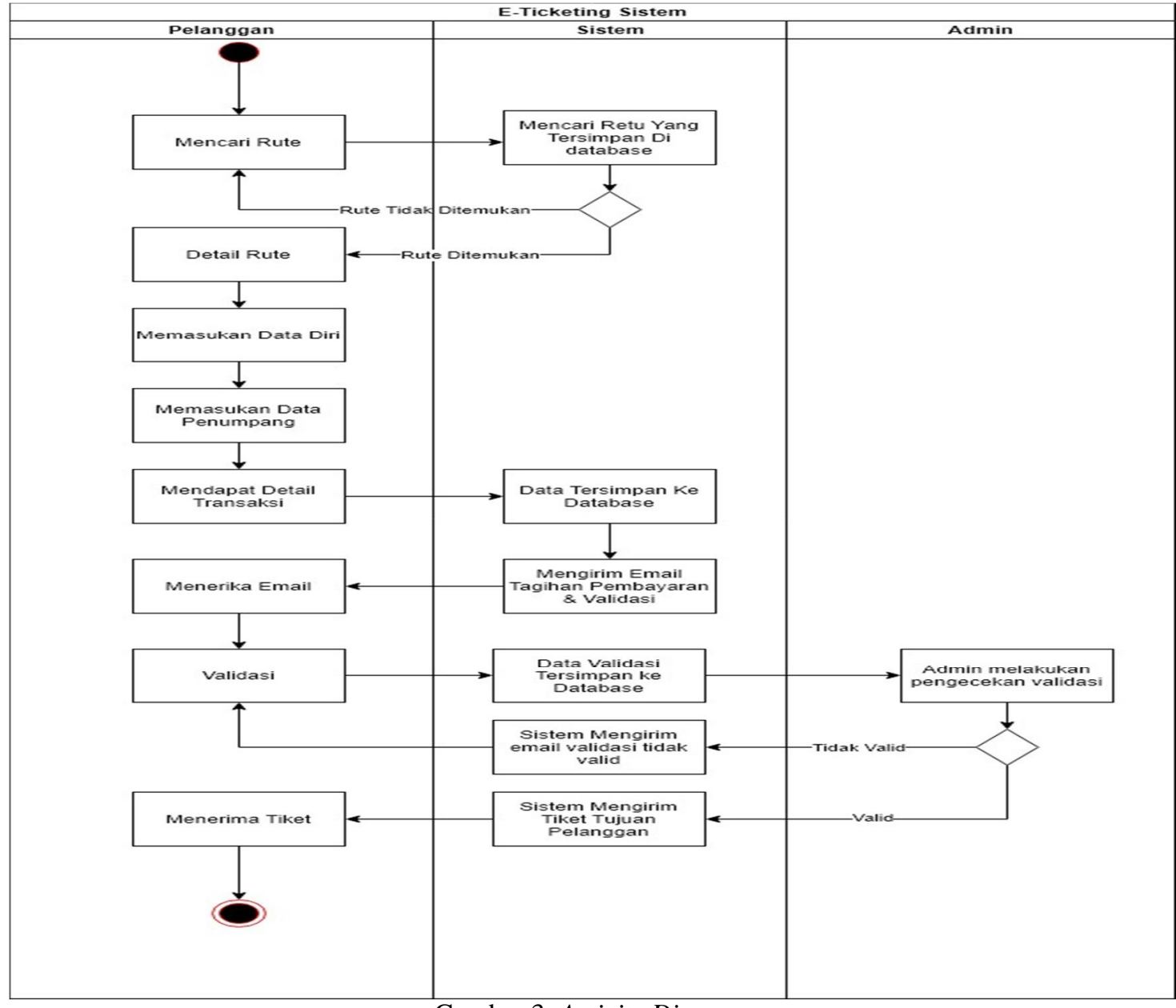

Gambar 3. Activity Diagram

\subsection{Hasil Penelitian}

Hasil penelitian diperolah dari coding. Berupa sebuah website e-ticketing, website eticketing ini menggunakan framework laravel yang mana didalam framework laravel terdapat sebauh fitur bawaan yaitu mail gateway yang digunakan untuk mengirimkan email. Framework laravel juga digunakan untuk tampilan halaman website, penggunaannya terletak pada sistem blade yang terdapat pada framework laravel, penggunaan sistem ini mempermudah dalam pembuatan tiap tiap tampilan yang ada pada website. Tampilan website e-ticketing dapat dilihat pada Gambar 4 - Gambar 12. 


\section{HOME NEWS SERVICE INFO}

\section{SELAMAT DATANG}

Silahkan Melakukan Pemesanan Tiket Dengan Form Dibawah Ini

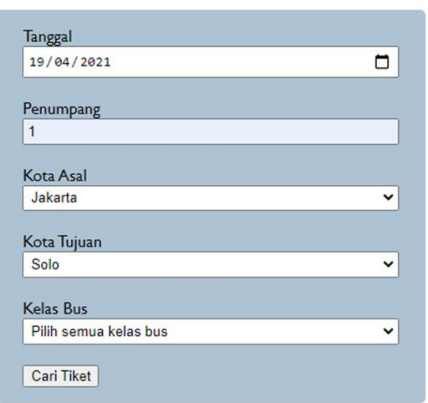

Gambar 4. Tampilan Cari Tiket

Pada Gambar 4 menunjukan tampilan cari tiket, tampilan ini digunakan oleh pelanggan untuk mencari tiket berdasarkan rute yang mereka masukan.

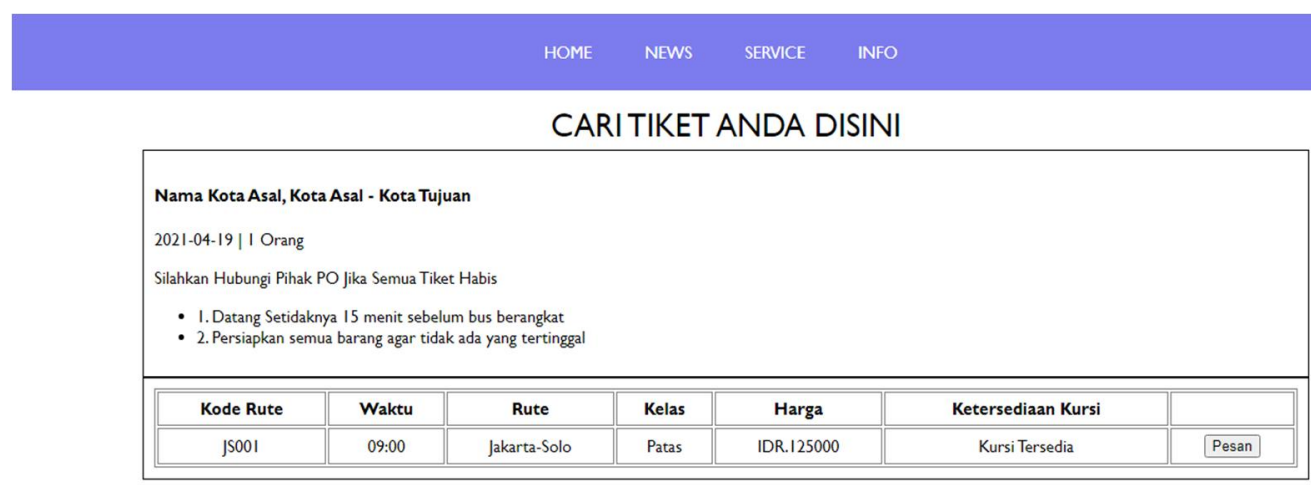

Gambar 5. Tampilan Rute yang Tersedia

Pada Gambar 5 tampilan rute yang tersedia digunakan untuk memperlihatkan hasil pencarian rute yang di masukan oleh user pada tampilan cari tiket jurusan. Hasil yang ditampilkan menandakan ketersediaan tiket pada rute yang dipilih. 


\section{HOME NEWS SERVICE INFO}

MASUKAN DATA DIRI ANDA UNTUK INFORMASI TIKET

DATA DIRI

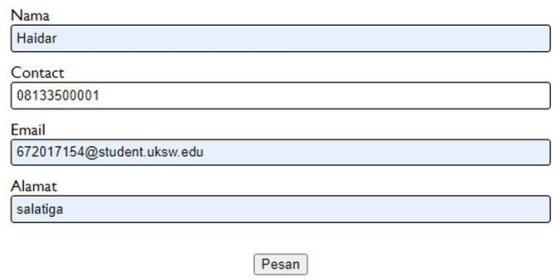

Gambar 6. Tampilan Mengisi Data Diri

Gambar 6 tampilan mengisi data diri berfungsi sebagai tempat registrasi pelanggan agar tiket yang telah dipesan bisa sampai ke tanggan pelanggan.

\section{HOME NEWS SERVCE INFO}

\section{MASUKAN DATA PENUMPANG}

DATA PENUMPANG

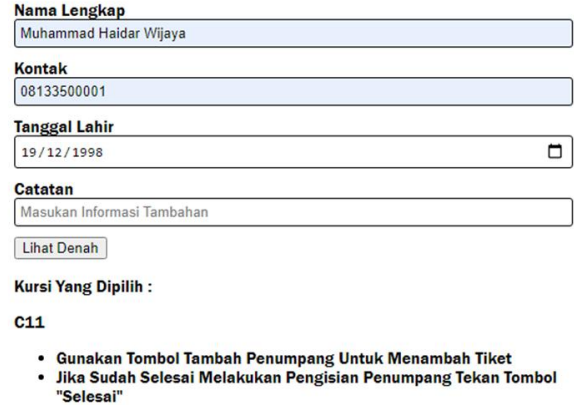
Jika Sudah
"Selesai"

Gambar 7. Tampilan Mengisi Data Diri Penumpang

Pada Gambar 7 tampilan mengisi data diri digunakan untuk menentukan usia dari pelanggan yang hendak memesan tiket, serta digunakan untuk menambahkan keperluan lain saat hendak menggunakan jasa bus. 


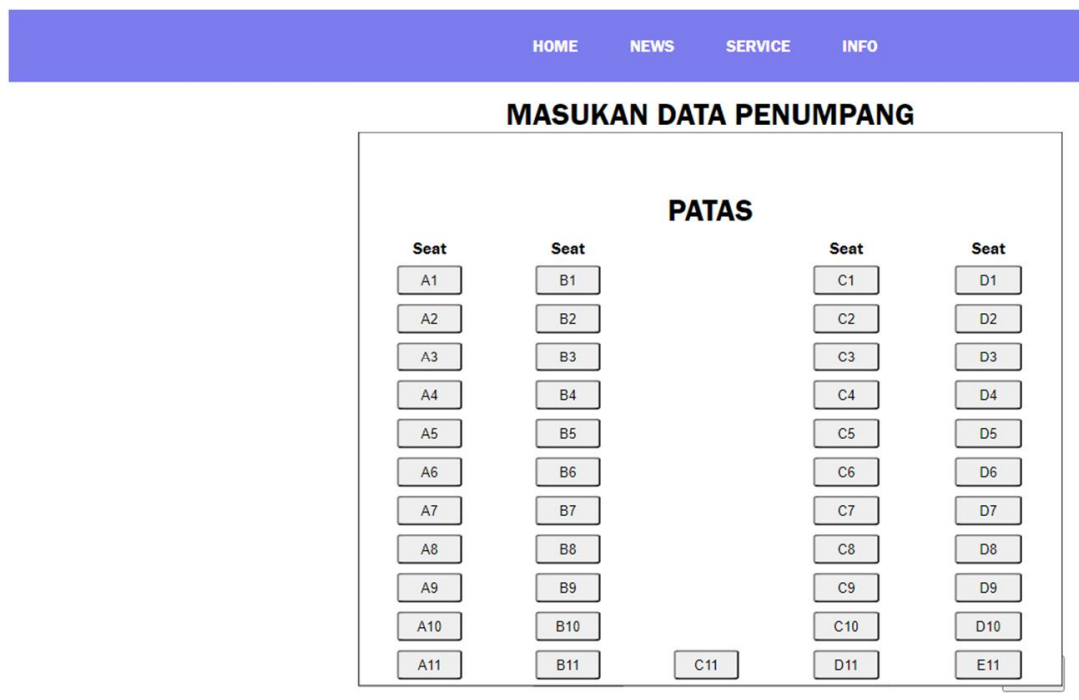

Gambar 8. Tampilan Memilih Tempat Duduk

Pada Gambar 8 tampilan memilih tempat duduk digunakan untuk mengecek tempat duduk yang tersedia dan digunakan oleh user untuk menentukan tempat duduknya secara mandiri.

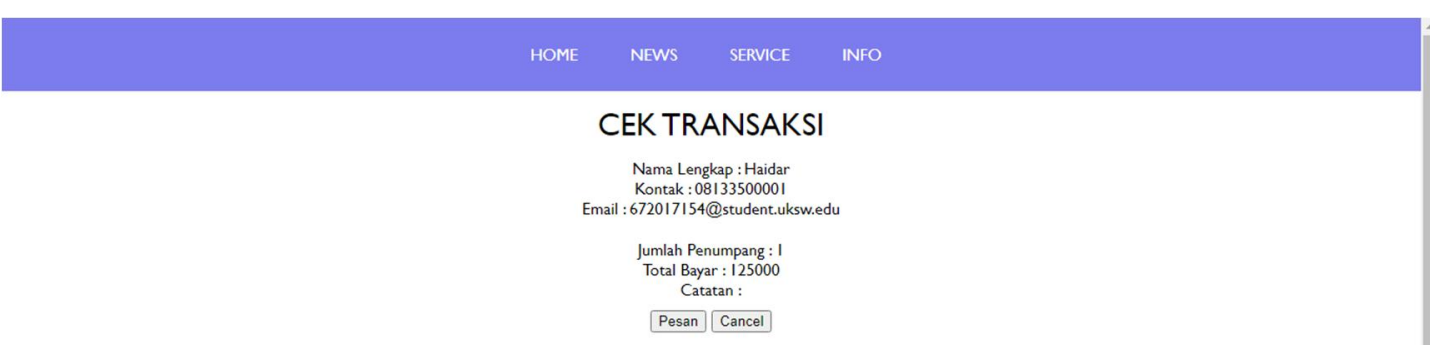

Gambar 9. Tampilan Cek Transaksi

Pada Gambar 9 Tampilan cek transaksi digunakan untuk melihat detail transaksi yang dilakukan oleh pelanggan, detail yang tercatat dalam cek trasaksi ini berupa nama pelanggan, kontak pelanggan, email pelanggan, serta jumlah penumpang dan total biaya yang dikeluarkan. 


\begin{tabular}{|c|c|c|}
\hline & Compose & \\
\hline 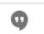 & Chats & \\
\hline$\infty$ & Scheduled & \\
\hline$\square$ & All Mail & \\
\hline 9 & Spam & \\
\hline - & Trash & \\
\hline- & Categories & \\
\hline$\$$ & Manage labels & \\
\hline+ & Create new label & \\
\hline Meet & & \\
\hline$=$ & New meeting & \\
\hline$\square$ & My meetings & \\
\hline \multicolumn{3}{|c|}{ Hangouts } \\
\hline 8 & Muhammad $\mathrm{Ha}$ & + \\
\hline & $\begin{array}{l}\text { No recent chats } \\
\text { Start a new one }\end{array}$ & \\
\hline & $\therefore 0$ & \\
\hline
\end{tabular}

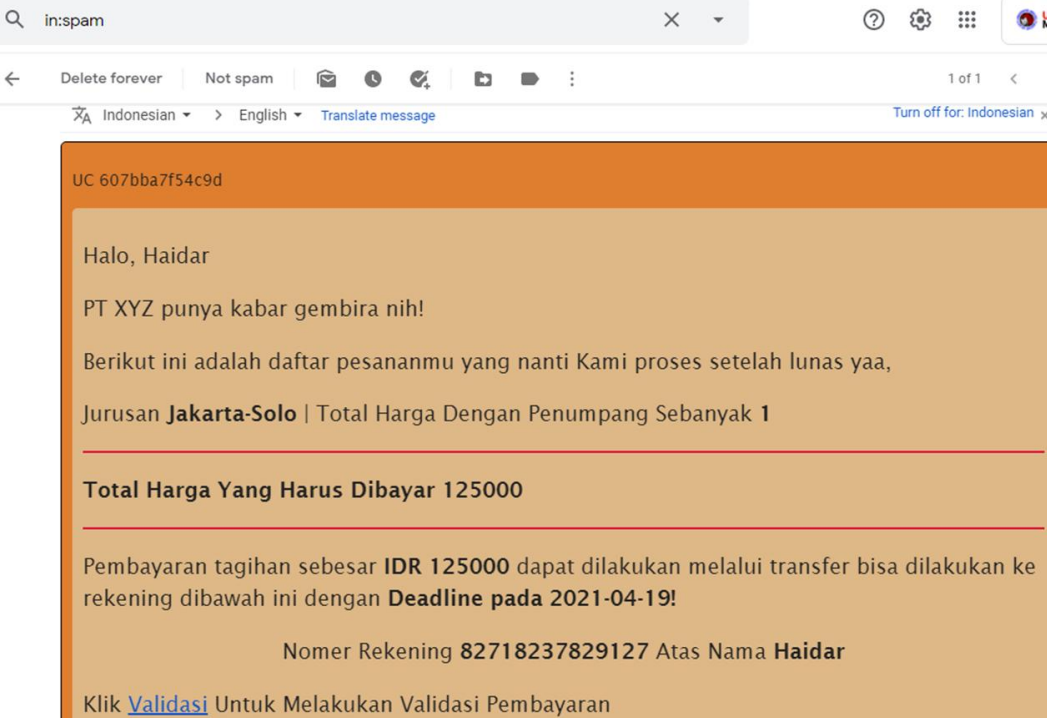

Gambar 10. Tampilan Pelunasan

Pada Gambar 10 tampilan pelunasan, pelanggan akan mendapatkan sebuah struk pelunasan yang dikirim melalui email yang didapat dari pelanggan saat mengisi form data diri, dalam form pelunasan ini berisikan link yang mengarah ke form validasi transaksi.

\section{HOME NEWS SERVICE INFO}

\section{SELAMAT DATANG}

Masukan Bukti Transfer Pembayaran Disin

\begin{tabular}{l} 
Unik Kode \\
607bba7f54c9d \\
Masukan Berkas \\
Pilih File 11140332_11..6247153_n.jpg \\
Kirim \\
\hline
\end{tabular}

Gambar 11. Tampilan Validasi Pelunasan Tagihan

Pada Gambar 11 tampilan validasi pelunasan, digunakan oleh pelanggan untuk memvalidasi transaksi yang telah mereka lakukan. Bukti validasi berupa file dengan format gambar yang diupload oleh pelanggan. 


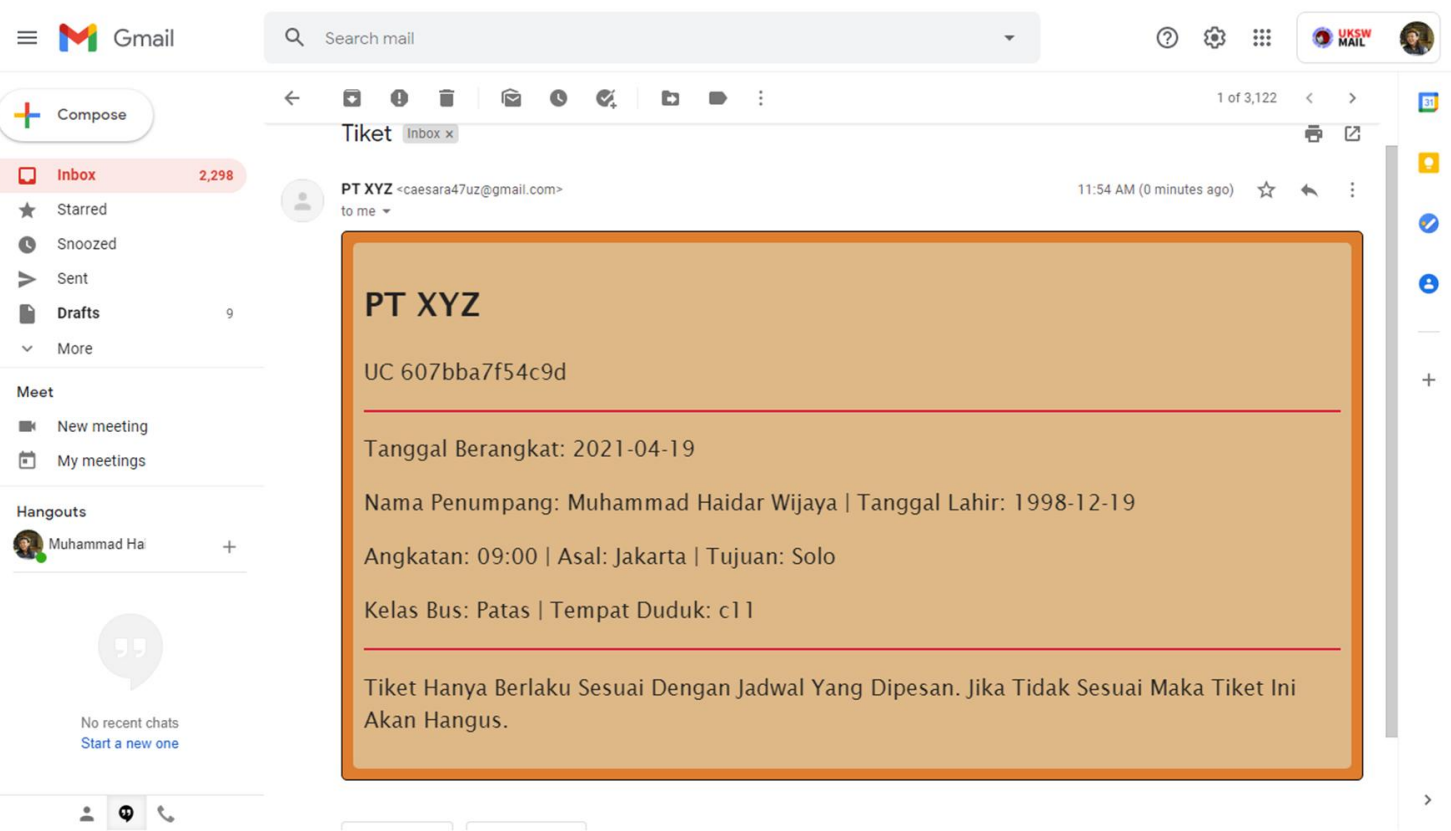

Gambar 12. Tampilan Tiket

Pada Gambar 12 tampilan tiket, pelanggan yang bukti transaksinya sudah divalidasi akan mendapat tiketnya melalui email. Tiket yang sudah jadi ini sudah bisa digunakan untuk menggunakan jasa layanan bus dengan rute yang dituju, tiket hanya berlaku sesuai dengan jadwal keberangkatan yang dipilih oleh pelanggan.

\subsection{Pengujian Sistem}

Pengujian terhadap sistem dilakukan dengan menggunakan metode blackbox, metode blackbox testing merupakan metode yang dipakai untuk melakukan uji sistem tanpa harus memperhatikan detail pada suatu system [10]. Dari aplikasi yang sudah jadi akan dilakukan beberapa pengujian pada form yang ada seperti yang ditampilkan pada Tabel 1.

Tabel 1. Identifikasi Pengujian

\begin{tabular}{|c|l|c|}
\hline No & \multicolumn{1}{|c|}{ Form } & Jenis Pengujian \\
\hline 1 & Form Cari Tiket & Black Box \\
\hline 2 & Form Rute Yang Tersedia & Black Box \\
\hline 3 & Form Data Diri & Black Box \\
\hline 4 & Form Data Diri Penumpang & Black Box \\
\hline 5 & Form Memilih Tempat Duduk & Black Box \\
\hline 6 & Form Cek Transaksi & Black Box \\
\hline 7 & Notifikasi Pelunasan & Black Box \\
\hline 8 & Form Validasi & Black Box \\
\hline 9 & Tiket & Black Box \\
\hline
\end{tabular}

Hasil dari pengujian aplikasi dengan menggunakan blackbox berdasarkan indentifikasi pengujian, ditampilkan pada Tabel 2. 
Tabel 2. Hasil Pengujian

\begin{tabular}{|c|c|c|c|c|c|}
\hline Identifikasi & Deskripsi & Cara Pengujian & Masukan & Hasil & Kesimpulan \\
\hline $\begin{array}{l}\text { Form Cari } \\
\text { Tiket }\end{array}$ & $\begin{array}{c}\text { Tampilan } \\
\text { untuk mencari } \\
\text { tiket }\end{array}$ & Mengisi form & Ketikan dan klik & $\begin{array}{l}\text { Pindah ke } \\
\text { tampilan } \\
\text { rute tiket } \\
\text { yang } \\
\text { tersedia }\end{array}$ & Sukses \\
\hline $\begin{array}{c}\text { Form Rute } \\
\text { Yang } \\
\text { Tersedia }\end{array}$ & $\begin{array}{c}\text { Tampilan } \\
\text { untuk rute } \\
\text { yang dicari }\end{array}$ & $\begin{array}{l}\text { Mengklik tombol } \\
\text { pesan }\end{array}$ & Klik & $\begin{array}{l}\text { Pindah ke } \\
\text { tampilan } \\
\text { data diri }\end{array}$ & Sukses \\
\hline $\begin{array}{c}\text { Form Data } \\
\text { Diri }\end{array}$ & $\begin{array}{l}\text { Tampilan } \\
\text { untuk } \\
\text { mengisi data } \\
\text { diri } \\
\end{array}$ & Mengisi form & Ketikan dan klik & $\begin{array}{l}\text { Pindah ke } \\
\text { tampilan } \\
\text { data diri } \\
\text { penumpang }\end{array}$ & Sukses \\
\hline $\begin{array}{c}\text { Form Data } \\
\text { Diri } \\
\text { Penumpang }\end{array}$ & $\begin{array}{l}\text { Tampilan } \\
\text { untuk mengisi } \\
\text { data diri } \\
\text { penumpang }\end{array}$ & Mengisi form & Ketikan dan klik & $\begin{array}{l}\text { Pindah ke } \\
\text { tampilan cek } \\
\text { transaksi }\end{array}$ & Sukses \\
\hline $\begin{array}{l}\text { Form } \\
\text { Memilih } \\
\text { Tempat } \\
\text { Duduk }\end{array}$ & $\begin{array}{c}\text { Tampilan } \\
\text { untuk memilih } \\
\text { tempat duduk }\end{array}$ & $\begin{array}{l}\text { Mengklik tombol } \\
\text { pilih tempat } \\
\text { duduk }\end{array}$ & Klik & $\begin{array}{c}\text { Mendapatka } \\
\mathrm{n} \text { informasi } \\
\text { tempat } \\
\text { duduk }\end{array}$ & Sukses \\
\hline $\begin{array}{l}\text { Form Cek } \\
\text { Transaksi }\end{array}$ & $\begin{array}{c}\text { Tampilan } \\
\text { untuk melihat } \\
\text { detail } \\
\text { transaksi }\end{array}$ & $\begin{array}{l}\text { Mengklik tombol } \\
\text { pesan }\end{array}$ & Klik & $\begin{array}{l}\text { Notifikasi } \\
\text { Tagihan } \\
\text { Muncul }\end{array}$ & Sukses \\
\hline $\begin{array}{l}\text { Notifikasi } \\
\text { Pelunasan }\end{array}$ & $\begin{array}{l}\text { Tampilan } \\
\text { untuk detail } \\
\text { pelunasan }\end{array}$ & $\begin{array}{c}\text { Notifikasi } \\
\text { terkirim ke email } \\
\text { pelanggan }\end{array}$ & Kirim email & $\begin{array}{c}\text { Email } \\
\text { tagihan } \\
\text { terkirim ke } \\
\text { pelanggan }\end{array}$ & Sukses \\
\hline $\begin{array}{c}\text { Form } \\
\text { Validasi }\end{array}$ & $\begin{array}{c}\text { Tampilan } \\
\text { untuk validasi } \\
\text { pelunasan } \\
\text { tagihan }\end{array}$ & $\begin{array}{l}\text { Memasukan file } \\
\text { bukti pembayaran }\end{array}$ & Klik & $\begin{array}{l}\text { Email Tiket } \\
\text { Terkirim ke } \\
\text { pelanggan }\end{array}$ & Sukses \\
\hline Tiket & $\begin{array}{l}\text { Tampilan tiket } \\
\text { yang dipesan } \\
\text { oleh } \\
\text { pelanggan }\end{array}$ & $\begin{array}{l}\text { Tiket terkirim ke } \\
\text { email pelanggan }\end{array}$ & Kirim email & $\begin{array}{c}\text { Email } \\
\text { berisikan } \\
\text { tiket }\end{array}$ & Sukses \\
\hline
\end{tabular}

Berdasarkan hasil dari pengujian dari tabel 2 semua form yang ada pada aplikasi sudah diujikan menggunakan metode blackbox dan diketahui semua form berjalan dengan lancar tanpa ada satu error pun terjadi. Dengan ini dapat disimpulkan bahwa aplikasi sudah bisa berjalan bisa berjalan dengan sesuai harapan. 


\section{KESIMPULAN}

Kesimpulan dari penelitian ini adalah sebuah sistem e-ticketing berbasis website. Dengan menggunakan sistem ini pelanggan tidak perlu lagi mendatangi agen bus untuk melakukan transaksi pembelian tiket, melainkan cukup dengan mengakses website e-ticketing maka transaksi dapat dilakukan kapanpun dan dimanapun, serta dapat mencegah terjadinya kerusakan pada tiket atau kehilangan tiket. Pengembangan website ini menggunakan framework laravel serta dikembangkan dengan model waterfall. Fitur yang terdapat dalam website ini antara lain cari tiket, rute yang tersedia, memilih tempat duduk dan mail gateway.

\section{SARAN}

Saran untuk pengembangan website e-ticketing untuk kedepannya, dapat meringkas beberapa fitur, seperti form pengisian data diri dan form pengisian data diri pelanggan. Seharusnya dapat digabung menjadi satu form tampilan, dengan digabung menjadi satu tampilan akan memberikan pengalaman penggunaan website yang lebih baik oleh pelanggan. Serta memperbaiki tampilan tiket yang telah dibeli oleh pelanggan agar tampillannya menjadi lebih baik.

\section{DAFTAR PUSTAKA}

[1] A. G. Kamaludin, N. Puspitasari, and D. G. Ginanjar, 2017, "Penerapan Sistem Tiket Elektronik Perusahaan Bus Antar Kota pada Terminal Terpadu,” J. Manaj. Bisnis Transp. Dan Logistik, Vol. 3, No. 3, pp. 301-310.

[2] Imam Rofi'i, Hendrawan, and P. A. Jusia, 2015, "Perancangan Aplikasi E-Ticketing pada," J. Ilm. Media Process., Vol. 10, No. 2, p. 519.

[3] Kartini and S. Popong, 2018, "Sistem Reservasi E-ticketing Pesawat Multi-tier T erintegrasi," $\quad$ pp. $8-9, \quad$ [Online]. Available: http://digilib.mercubuana.ac.id/manager/t!@file_artikel_abstrak/Isi_Artikel_1840621570 69.pdf.

[4] C. Ciksadan1, A. Rakhman, and I. M. Safira, 2019, "Rancang Bangun Aplikasi ETicketing Travel Antar Kota Berbasis Android,” Jurasik (Jurnal Ris. Sist. Inf. dan Tek. Inform., Vol. 4, No. 1, p. 151, doi: 10.30645/jurasik.v4i1.128.

[5] R. Dilla and V. I. Delianti, 2020, "Jurnal Vocational Teknik Elektronika dan Informatika," Vol. $8, \quad$ No. $\quad 1, \quad$ [Online]. Available: http://ejournal.unp.ac.id/index.php/voteknika/index.

[6] Aldonis and Johan, 2019, "Perancangan Sistem Informasi E-Ticketing pada Bus Trans Metro Pekanbaru Menggunakan QR Code Berbasis Web,” J. Mhs. Apl. Teknol. Komput. dan Inf., Vol. 1, No. 3, pp. 141-147, [Online]. Available: http://www.ejournal.pelitaindonesia.ac.id/JMApTeKsi/index.php/JOM/article/download/ $524 / 365 /$.

[7] J. Hutahaean and E. A. Purba, 2016, "Rancangan Bangun E-Ticket Bioskop Dengan Metode Waterfall Berbasis Web," Riau J. Comput. Sci., Vol. 2, No. 2, pp. 51-58.

Muhammad, et., al [Perancangan Aplikasi E-Ticketing pada Agen Bus Berbasis Website Menggunakan Laravel] 
[8] M. Arifin and R. H. H. Hs, 2017, “Perancangan Sistem Informasi Pusat Karir Sebagai Upaya Meningkatkan Relevansi Antara Lulusan Dengan Dunia Kerja Menggunakan UML Muhammad,” IC-Tech, Vol. XII, No. 2, pp. 42-49.

[9] M. Arifin, S. Slamin, and W. E. Y. Retnani, 2017, "Penerapan Metode Certainty Factor Untuk Sistem Pakar Diagnosis Hama dan Penyakit pada Tanaman Tembakau,” Berk. Sainstek, Vol. 5, No. 1, p. 21, doi: 10.19184/bst.v5i1.5370.

[10] A. A. Arwaz, T. Kusumawijaya, R. Putra, K. Putra, and A. Saifudin, 2019, "Pengujian Black Box pada Aplikasi Sistem Seleksi Pemenang Tender Menggunakan Teknik Equivalence Partitions," J. Teknol. Sist. Inf. dan Apl., Vol. 2, No. 4, p. 130, doi: 10.32493/jtsi.v2i4.3708. 